\title{
Cardiac surgery residency in Brazil: How to deal with the challenges of this unique specialty
}

\author{
Rodolfo V. Rocha, MD, ${ }^{a}$ and Rui M. S. Almeida, MD $^{\mathrm{b}}$
}

\footnotetext{
From the a Division of Cardiac Surgery, Peter Munk Cardiac Centre, Toronto General Hospital, University of Toronto, Ontario, Canada; and ${ }^{\mathrm{b}}$ Division of Cardiovascular Surgery, Western Parana State University, Cascavel, Brazil.

Received for publication Aug 4, 2017; revisions received March 22, 2018; accepted for publication May 20, 2018; available ahead of print July 3, 2018.

Address for reprints: Rodolfo V. Rocha, MD, 200 Elizabeth St, 4N-432, Toronto, Ontario, M5G 2C4 Canada (E-mail: rod.rocha@mail.utoronto.ca).

J Thorac Cardiovasc Surg 2018; 156:2227-32

0022-5223/ $\$ 36.00$

Copyright (c) 2018 by The American Association for Thoracic Surgery

https://doi.org/10.1016/j.jtcvs.2018.05.075
}

The first Brazilian open procedure, under cardiopulmonary bypass, was performed by Dr Felipozzi, in $1955 .{ }^{1}$ Since then, Brazilian surgeons have contributed to the cardiac surgery subspecialty with innumerous novel procedures. In 1975, Dr Jatene pioneered the arterial switch operation. ${ }^{2}$ This technique remains the standard of care treatment for transposition of great vessels. Dr Buffolo, along with Dr Benetti, from Argentina, described an alternative for coronary artery revascularization under cardiopulmonary bypass, the off-pump coronary artery bypass grafting, in 1985. ${ }^{3}$ Dr Batista reported a partial left ventriculotomy for the surgical treatment of left ventricle aneurysm in nonischemic dilated cardiomyopathy. ${ }^{4}$ Recently, Dr Da Silva described the cone procedure, which is now the preferred method for correction of Ebstein's anomaly. ${ }^{5}$

Currently, the national case volume, embracing all cardiac surgical procedures, in Brazil is approximately 100,000 per year. ${ }^{6}$ Among these interventions, the highest percentage is represented by coronary artery bypass grafting, followed by valve surgery, pacemaker or implantable cardioverter/defibrillator, congenital, aortic procedures, heart transplantation, and others.

Throughout the past decades, cardiac surgery has changed and evolved dramatically. In Brazil, this scenario is not different. Therefore, the training of contemporary cardiac surgeons is being modified to adapt to current demands: residency curriculum reformulation, with more time devoted to endovascular and invasive cardiology rotations; creation of national workshops to expose the resident to novel techniques; and elimination of general surgery requirement to apply for cardiac surgery residency. We present the cardiac surgery residency experience in Brazil and how the residency program is changing to provide adequate training to future surgeons.

\section{DETAILS OF TRAINING}

\section{Residency Options and Recruitment Process}

In Brazil, cardiac surgery residency has a separate pathway from thoracic and vascular surgery. The Brazilian

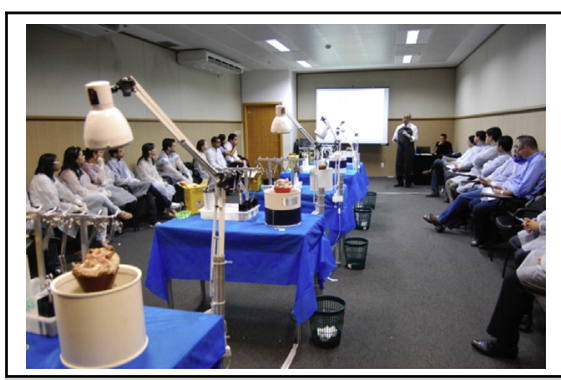

Cardiac surgery residency hands-on course. BSCVS member describing the surgical technique to the residents in the "hands-on" course.

Central Message

We present the cardiac surgery residency experience in Brazil and how the residency program is changing to provide adequate training to future surgeons.

See Editorial Commentary page 2233.

Society of Cardiovascular Surgery (BSCVS) and the Brazilian Ministry of Education (BME) are responsible for regulating all national residency programs, ensuring the trainees receive the minimum training required to become a specialist.

There are 228 cardiac surgery residency positions offered each year. ${ }^{7}$ Two tracks are available to become a fully trained cardiac surgeon in Brazil: the traditional and the integrated. The traditional track requires completion of 2 years of general surgery residency before initiation of cardiac surgery specialization. Recently, the integrated track emerged as an alternative, with no requirement of previous general surgery training, but with a longer cardiac surgery training period (5 years). A total of 96 of 228 positions (42\%) are assigned to the integrated track, leaving the traditional with the remaining 132 of 228 positions (58\%) per year. ${ }^{8}$ A total of 77 institutions offer cardiac surgery residency in Brazil, with 54 of $77(70 \%)$ being academic centers.

As in other countries, it has been increasingly difficult to attract new trainees to this subspecialty. ${ }^{9}$ The reasons are similar: long training and more procedures being performed by other specialties. On a recent census by the BSCVS, the number of successful applicants was 62 of 228 (27\%), with $60 \%$ joining cardiac surgery residency programs in the traditional track and $40 \%$ joining integrated programs. ${ }^{10}$

Most positions are filled by Brazilian national graduates. Currently, there are also international medical 
graduates from Peru, Bolivia, and Argentina undergoing training in Brazil. Conversely, there are Brazilian medical graduates being trained in other countries, mainly in North America and Europe. The 2 residency tracks (traditional and integrated) have structural differences, as described next.

\section{Traditional Track}

The traditional track is financially sponsored and certified by BME, and regulated by the BSCVS and BME. The candidate becomes eligible after completion of a general surgery residency program. During the 2-year Brazilian general surgery residency program, the resident is allocated, mainly, to general surgery. Nevertheless, during the first year, as part of mandatory rotations, the resident is exposed to urology, vascular, and thoracic surgery for 1 month in each subspecialty.

All cardiac surgery residency applicants must undertake a multiple-choice test, which includes general medicine topics. This exam is responsible for $90 \%$ of the candidate's final mark. The remaining $10 \%$ is determined by curriculum analysis and an interview.

The surgical training lasts 4 years and takes place at Brazilian public hospitals. The majority of patients derive from our national universal health care system, the Brazilian National Health Service (NHS). After the 4-year program, residents are recommended to spend an additional year, as part of a fellowship, in a cardiac surgery subspecialty of their choice (pediatric, endovascular, advanced heart failure/ heart transplantation, arrhythmia), although it is not mandatory.

The BME inspects all public hospital centers. The evaluation occurs on a regular basis, but differs for every institution. The evaluation interval will depend on previous reports from each center and how strictly the institution has adopted the requirements. The report should include the following: number of cardiac surgeries in the previous year; number of procedures performed by the resident as primary surgeon and first assistant; appropriateness of ward, intensive care unit, and operating room facilities; and number of diagnostic and invasive cardiac procedures performed.

After completion of residency training, trainees will obtain BME certification, allowing them to practice, as cardiac surgeons, for NHS patients only, at public hospitals. The Brazilian government, through the BME, enforces such restriction in an effort to increase the number of surgeons providing care to NHS patients. If the trainee seeks to care for patients with private insurance, at private hospitals, they need to become board certified, because most private insurance companies will require it. To obtain Brazilian board certification, the surgeon needs to apply to the Brazilian Cardiovascular Surgery Board Examination (BCVSBE).

\section{Integrated Track}

The integrated track is financially sponsored by each institution offering the program. It is certified and regulated by the BSCVS. There is no need of prior general surgery residency.

The selection process adopted is the same as the traditional track.

The 5-year program is undertaken at Brazilian private hospitals that offer care for both NHS and private insurance patients. In their fifth year, residents decide if they want to spend the year in a cardiac surgery subspecialty (pediatric, endovascular, advanced heart failure/heart transplantation, arrhythmia) or in general cardiac surgery.

The BSCVS inspects and evaluates all private hospital centers using the same evaluation criteria used by the BME in the traditional track.

After completion of residency training, trainees are required to pass the BCVSBE to care for any patient, from the NHS or individuals with private insurance.

Advantages of the integrated track include more time dedicated to cardiac surgery (5 years). With an additional year of cardiac surgery case exposure, in a shorter overall residency training period (5 vs 6 years), the trainee would, theoretically, be better prepared to enter the job market or engage in a cardiac surgery fellowship in the sub-area of choice. Nevertheless, there are no data to document the advantage of either track towards improving postresidency job opportunities or career success.

\section{PROGRAM CURRICULUM}

For both tracks, the BSCVS requires the resident to spend $90 \%$ of the program in cardiac surgery-related areas, including preoperative, intraoperative, and postoperative care, cardiac intensive care unit, cardiac imaging, and invasive cardiology rotations. For the remaining $10 \%$, the resident is assigned to thoracic and vascular surgery. No general surgery rotation is required.

After each different rotation and every 3 months, faculty must evaluate the trainees on a "performance scale," which includes 14 items encompassing technical skills, knowledge, and relationship abilities (Table 1) and report to the BSCVS.

The resident must meet all established requirements, including the number of surgeries performed as first surgeon and as first assistant. For cases in which the resident assumes a first assistant role, it is recommended to allow the trainee to perform all surgical procedures and, only for the core surgical moment, to be first assistant. During the first years, additional specific requirements are necessary, such as harvesting conduits, performing sternotomies, and vascular cannulation.

The maximum number of working hours is 60 per week, including a 24-hour "on call" shift, totaling 2800 to 
TABLE 1. Cardiac surgery resident evaluation form

\begin{tabular}{l} 
Question \\
\hline Resident's performance on \\
Seminar presentations \\
Rounds and case presentations \\
Dexterity \\
Interest \\
Formulating a diagnosis \\
Elaborating a treatment plan \\
Keeping the chart's relevant information \\
organized \\
Relationships \\
Follows the institution's rules \\
Interaction with patients and their family members \\
Interaction with co-workers \\
Proactiveness \\
Follows an established schedule \\
Ethical conduct \\
Wears adequate and proper clothing \\
Final analysis and comments \\
\hline
\end{tabular}

3200 hours per year ${ }^{11}$ in both tracks. Unfortunately, these hours are not strictly followed by some institutions, and as a result, hours are stretched out of the records. In an effort to overcome the lack of strict adoption of regulating hours, the BSCVS is reaccrediting all training centers.

\section{BOARD CERTIFICATION}

To become board certified by the BSCVS, the resident must pass the BCVSBE. The applicant must have completed their training and performed, during their residency, a minimum of 100 mid-complexity surgeries as a primary surgeon (ie, valve replacement or coronary artery bypass), with at least half of them under cardiopulmonary bypass. According to the BSCVS internal statistics, the average case load performed by a resident, as primary surgeon, is 150 cardiopulmonary bypass cases, with anecdotal cases of failure to reach the minimum number of cases required. Despite the additional year of cardiac surgery residency in the integrated pathway, there is no difference in the final number of cases performed compared with the traditional track.

The candidate must also obtain continued medical education credits from the Brazilian Journal of Cardiovascular Surgery, before exam application, by answering questions from continued medical education articles. ${ }^{12}$ The current BCVSBE consists of 3 steps:

- First step: A written exam: 3 open-ended and 55 multiplechoice questions. Apart from these, there are 20 additional questions regarding surgical algorithms or diagnostic images. The passing score is $70 \%$. The average passing rate is $60 \%$ over the past 5 years.
- Second step: Practice assessment: A BSCVS member is designated to visit the applicant's training center, to evaluate the candidate's abilities and clinical judgment, while operating an elective mid/high-complexity cardiac case, under cardiopulmonary bypass (ie, valve replacement or coronary artery bypass). Table 2 summarizes the evaluation criteria for the practice examination. The average passing rate for this step is $95 \%$.

- The final step is to submit a scientific manuscript to be appreciated by reviewers from the Deliberative Committee of the BSCVS.

The candidate has 6 months to finish all 3 steps. After successful completion of the 3 BCVSBE steps, the cardiac surgeon becomes board certified and is able to perform all procedures unrestrictedly.

The second step (practice assessment) is also a method to evaluate the residency program, ensuring the resident receives appropriate training, enough to be capable to perform a cardiac procedure independently. If the candidate fails the practice assessment, the program director is informed and the reasons for failure are discussed. The candidate will then be able to perform surgical procedures only under the supervision of a board-certified surgeon, being required to undertake the same rotations of a senior cardiac surgery resident. The program director and trainee will be responsible to reschedule the exam whenever both are confident that a mid-complexity case can be performed independently. A maximum of 3 attempts is allowed. In case of 3 consecutive failures, the resident becomes ineligible for board certification and independent practice, and the residency program undergoes an especial BSCVS assessment to evaluate the quality of training offered. As mentioned, the pass/failure rate for step 2 is $95 \%$, and only few cases have occurred of 3 consecutive fails from the same trainee.

\section{CHALLENGES OUR EDUCATIONAL SYSTEM IS FACING}

Cardiac surgeons are now performing minimally invasive and endovascular procedures to guarantee a safer procedure and to secure their position in the competitive medical field. In Brazil, there is no regulation preventing the surgeon from performing these novel procedures. However, there has been increased scrutiny from hospitals' managers and insurance companies, assigning and reimbursing only surgeons who undertook proper training/courses for the new procedure. For this reason, a number of trained and fully certified surgeons have been seeking additional training. ${ }^{13}$ In an effort to incorporate these new procedures into the residents' training, the BSCVS has created national-level initiatives. ${ }^{14}$

A clear deficiency in our current residency system is the existence of 2 distinct and disparate tracks toward becoming a trained cardiac surgeon. The lack of uniformity affects not 
TABLE 2. Practice examination Brazilian Society of Cardiovascular Surgery

Rate the candidate, from 1 to 10 , on each of the 5 main topics:

1- Candidate's communication skills and attitude

2- Case presentation:

History and physical exam

Investigations (imaging)

Surgical indication according to guidelines

Surgical mortality and major adverse cardiac and cerebrovascular event risk

Planned surgical intervention "step-by-step"

Dealing with intraoperative complications

3- Surgery:

Patient monitoring

Preoperative perfusion strategy discussion with perfusionists

Preoperative presentation of myocardial protection alternatives

Candidate's interaction with other team members

Candidate's leadership role in operating room

Cardiopulmonary bypass and aortic crossclamp time (if applicable)

Candidate's dexterity

Ability to wean patients from cardiopulmonary bypass safely

Intraoperative complications: Could it be avoided? How the candidate managed

4- Transportation to intensive care unit:

Candidate's ability to monitor patient's hemodynamic status

Hand over report to intensivist

5- Postoperative course:

Summary of patient's hospital stay

Candidate's management of patient:

- While in the intensive care unit

- While in the ward

- After discharge to $30 \mathrm{~d}$ postoperatively

Weight of each topic:

$1 \%-10 \%$

$2 \%-20 \%$

$3 \%-50 \%$

$4 \%-5 \%$

$5 \%-15 \%$

Final analysis and comments

only the trainees but also the national healthcare system, which relies on certified professionals for the care of its population.

\section{OVERCOMING THE CHALLENGES}

On May 2017, after a 10-year negotiation between the BME and the education committee of the BSCVS, a decision was made to uniformly offer the integrated track only for cardiac surgery trainees throughout the country. All Brazilian cardiac surgery residency programs are now regulated by the BSCVS and certified by both the BME and BSCVS, starting in 2018. This change was only adopted by the cardiac surgery residency programs. The other surgical specialties (thoracic, vascular surgery) did not seek any change from their current system of 2 distinct residency tracks. The residency program curriculum was
TABLE 3. New cardiac surgery program curriculum

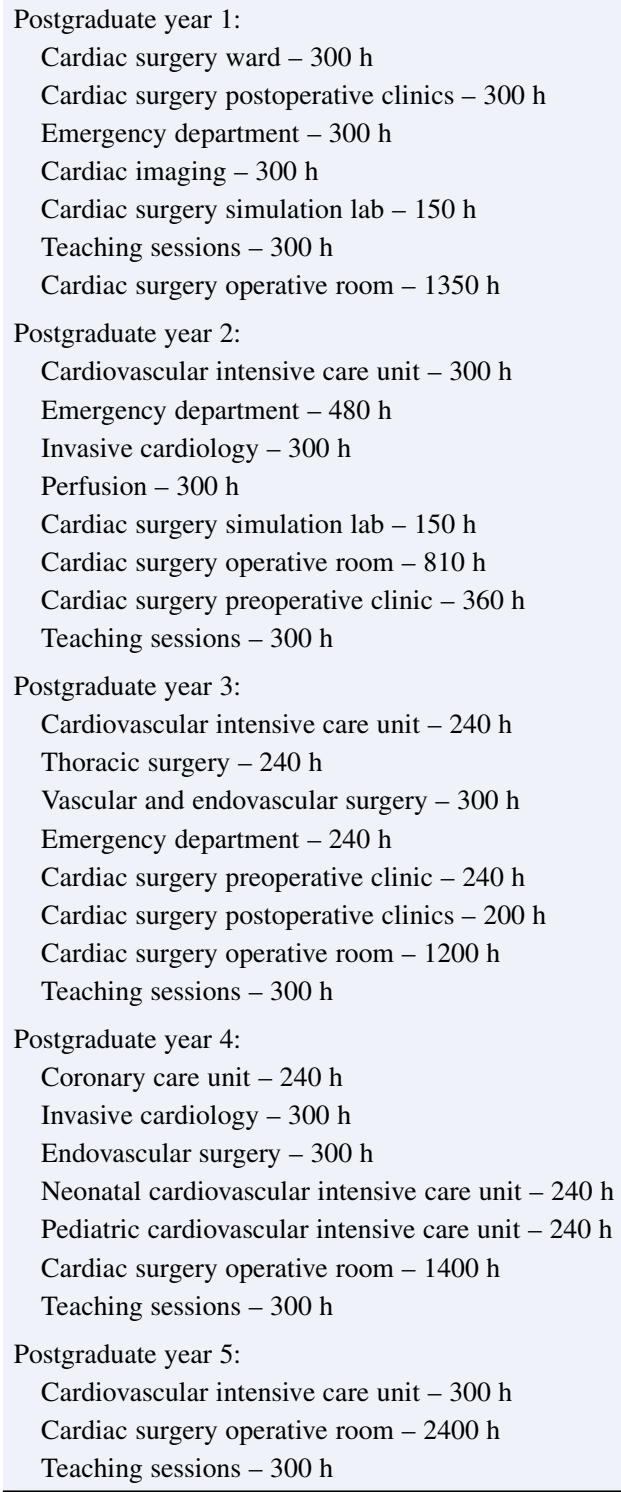

also reformulated. There will be increased hours dedicated to endovascular and invasive cardiology rotations (Table 3). A new BSCVS yearly written examination will now become part of the board certification process to ensure continuous assessment of the program and resident. The performance scale (Table 1) continues as part of the resident's evaluation by the BSCVS. The number of procedures required for the final BCVSBE was increased to 150 cardiac surgeries, with at least half being under cardiopulmonary bypass. The BCVSBE steps remain unchanged.

Historically, the number of cardiac surgery residency positions has been 228 per year. This number has been the same since the 1990s. However, Brazilian cardiac 


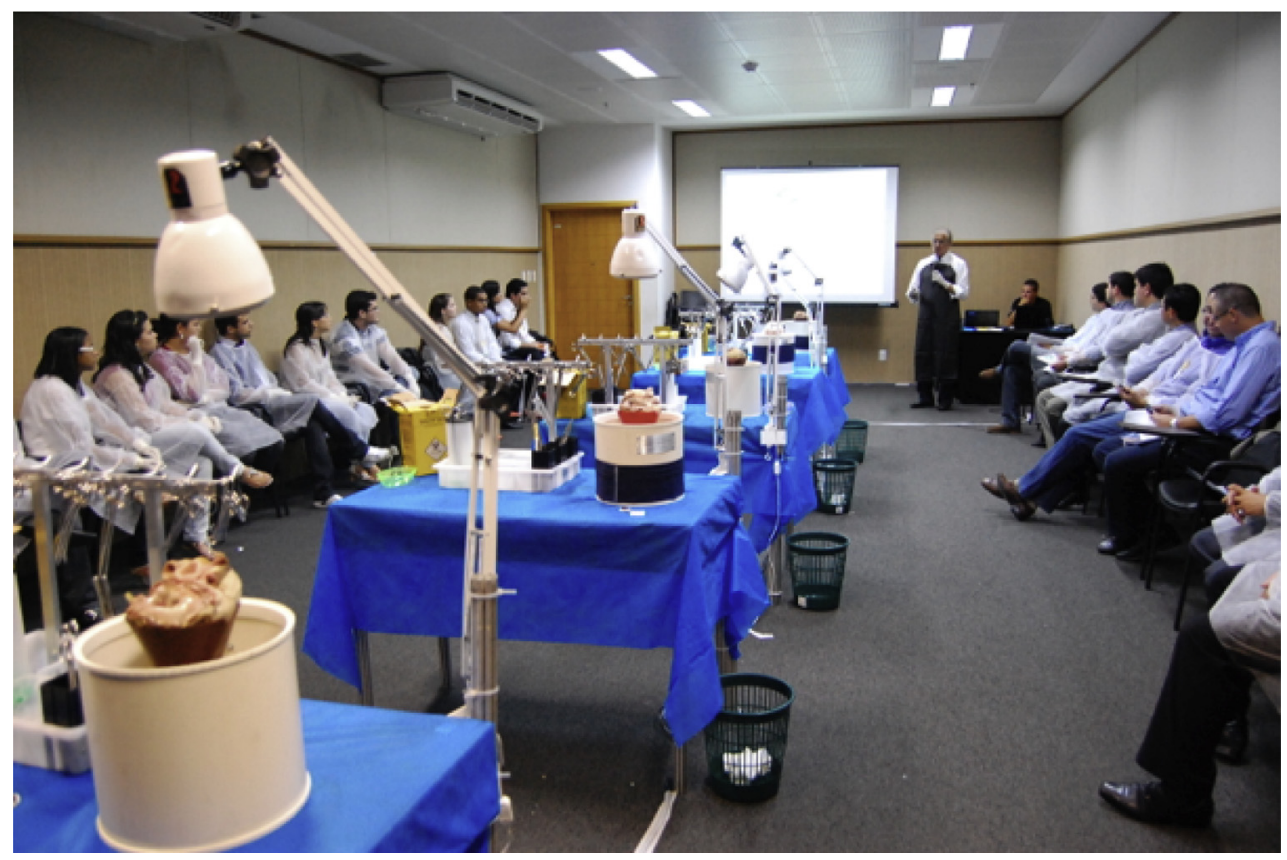

FIGURE 1. Cardiac surgery residency hands-on course. BSCVS member describing the surgical technique to the residents in the "hands-on" course.

surgery cases $(100,000 / y)$ and the number of residency applicants have decreased compared with previous decades. The BSCVS has debated whether to decrease the number of residency positions. With the novel unified residency program, sponsored by both BME and BSCVS, the number of applicants is expected to increase. Moreover, the reformulation of the program curriculum is intended to provide more training in novel procedures (minimally invasive, endovascular), with the objective of inserting newly trained cardiac surgeons in the market for these types of procedures, increasing the annual cardiac surgery volume.

Brazilian centers with high-volume cases of each "new procedure" have been selected to offer elective courses for trainees and young surgeons. This includes institutions with endovascular surgery, minimally invasive surgery, and mechanical circulatory support programs. In addition, the BSCVS hosts 4 wet lab courses per year for residents, at the "Technical Skills Lab" in its headquarters in Sao Paulo. Furthermore, national academic institutions offer annual workshops for residents, where they can improve their operative skills on simulators. Most of them have only a symbolic fee for subscription, with the majority of the cost subsidized by residency institutions or by an industry grant.

The BSCVS annual scientific meeting has introduced the "Hands On" section. ${ }^{15}$ Ten participants are assigned to an expert surgeon in the designated cardiac surgery sub-area. The trainee is encouraged to practice all the surgical steps (Figure 1).

\section{CONCLUSIONS}

New challenges have emerged in the training of the contemporary cardiac surgeon. A shorter and more effective training is required. New emerging techniques need to be incorporated in the residency program without compromising appropriate basic training. It is the responsibility of staff surgeons and each national society, such as the BSCVS, to take the lead and guide the new generation toward the bright future of our specialty.

\section{Conflict of Interest Statement}

Authors have nothing to disclose with regard to commercial support.

\section{References}

1. Gomes WJ, Saba JC, Buffolo E. 50 anos de circulação extracorpórea no Brasil: Hugo J. Felipozzi, o pioneiro da circulação extracorpórea no Brasil. Rev Bras Cir Cardiovasc. 2005;20:1-6.

2. Jatene AD, Fontes VF, Paulista PP, de Souza LC, Neger F, Galantier M, et al. Successful anatomic correction of transposition of the great vessels. A preliminary report. Arq Bras Cardiol. 1975;28:461-4.

3. Buffolo E, Andrade JC, Succi J, Leão LE, Gallucci C. Direct myocardial revascularization without cardiopulmonary bypass. J Thorac Cardiovasc Surg. 1985; $33: 26-9$.

4. Batista RJ, Santos JL, Takeshita N, Bocchino L, Lima PN, Cunha MA. Partial left ventriculectomy to improve left ventricular function in end-stage heart disease. $J$ Card Surg. 1996;1196-7.

5. da Silva JP, Baumgratz JF, da Fonseca L, Franchi SM, Lopes LM, Tavares GM, et al. The cone reconstruction of the tricuspid valve in Ebstein's anomaly. The operation: early and midterm results. J Thorac Cardiovasc Surg. 2007;133: 215-23.

6. Brazilian national surgical case volume. Available at: http://tabnet.datasus.gov. br/cgi/tabcgi.exe?sih/cnv/piuf.def. Accessed March 21, 2018. 
7. 2015 Brazilian residency positions for cardiovascular surgery. Available at: www.sbccv.org.br/residentes/mec.html. Accessed March 21, 2018.

8. 2015 Brazilian integrated cardiovascular surgery residency centers. Available at: www.sbccv.org.br/residentes/centrotreinamento.asp. Accessed March 21, 2018.

9. Vaporciyan AA, Reed CE, Erikson C, Dill MJ, Carpenter AJ, Guleserian KJ, et al. Factors affecting interest in cardiothoracic surgery: survey of North American general surgery residents. J Thorac Cardiovasc Surg. 2009;137:1054-62.

10. 2011 national resident census for cardiovascular surgery. Available at: www. sbccv.org.br/residentes/censos.asp. Accessed March 21, 2018.

11. Education and training program of the Brazilian Society of Cardiovascular Surgery. Available at: www.sbccv.org.br. Accessed March 21, 2018.
12. Almeida RM, Leal JC, Murad H, Jatene F, Braile D. Regimento interno para a obtenção do título de especialista - Sociedade Brasileira de Cirurgia Cardiovascular. Rev Bras Cir Cardiovasc. 2013;28:306-7.

13. Gomes WJ, Almeida RM, Braile DM. The rescue surgeon. Rev Bras Cir Cardiovasc. 2009;24:III-IV.

14. Gomes WJ. Innovation and excellence: changing to prevail the Brazilian cardiovascular surgery. Rev Bras Cir Cardiovasc. 2013;28:III-IV.

15. Barbosa GV, Brandão CM, Nina VJ. Hands on as educational process in cardiovascular surgery. In: Maluf M, Evora PRB, eds. Cardiac Surgery: A Commitment to Science, Technology and Creativity. Rijeka: InTech Europe; 2014:35-57I. 